\title{
Lateralization Pattern in Patients with Schizophrenia and Depression
}

\author{
Dr. Braj Bhushan*, Mr. Anand Prakash ${ }^{\dagger}$ and Dr. Rajneesh Gupta \\ "Indian Institute of Technology, Kanpur (UP), India \\ ${ }^{\dagger}$ University of Gondar, Ethiopia \\ \#Manobal Hospital, Amritsar, India
}

(Received 28 December 2007 and accepted 22 January 2008)

\begin{abstract}
The objective of this study was to see the incidence of peripheral laterality in schizophrenics and depressed patients. A total of 147 male subjects (29 schizophrenics, 38 depressed, 80 non-patient controls) were asked to indicate their preferences for hand, foot, eye, and ear on the Sidedness Bias Schedule. The correlations among the laterality quotients (LQ) in all the three groups were positive and highly significant except the foot-eye correlation in the non-patient controls. The left and mixed-handed schizophrenics and depressed subjects exhibited extreme left and mixed preference for foot, eye, and ear, respectively. Hand and ear preferences emerged as the predictors of schizophrenia and depression in the logistic regression analysis. The findings indicate a possible relationship between psychopathology and extreme left-mixed dominance.
\end{abstract}

KEY WORDS: Peripheral laterality; Schizophrenia; Depression

\section{INTRODUCTION}

Since Flor-Henry ${ }^{1}$ advocated the relationship between lateralization and psychopathology and Hicks and Barton ${ }^{2}$ reported left handedness in $28 \%$ of the people with serious mental disorders lateralization has been studied in relation to different types of psychosis ${ }^{\mathbf{3 , 4}}$. Studies have also indicated association between depressive symptoms and schizophrenia ${ }^{\mathbf{5 , 6 , 7}}$. Such research gained impetus after propositions of the GBG model (Geschwind-Behan-Galaburda model) ${ }^{\mathbf{8 - 1 1}}$. This model suggests a causal association between prenatal testosterone levels and an array of psycho-biological phenomena.

The relationship between peripheral indices of laterality, especially handedness and schizophrenia $^{\mathbf{1 2 , 1 3}}$ as well as depression and lateralized cognitive functions $\mathbf{s}^{\mathbf{1 4} 15}$ has been a subject of interest for last couple of decade. Interestingly enough neither of the two pathologies have yielded a conclusive association with lateralization. Initial studies indicated an increased proportion of left and mixed handedness among schizophrenic patients ${ }^{16}$, but recent research attests its link with mixed handedness ${ }^{17,18}$ and not left-handedness. Chapman and Chapman ${ }^{19}$ reported common observation of mixed handedness in individuals measuring high on psychosis-proneness and schizotype, a finding that was further supported by Kim et $\mathbf{~ a l}^{\mathbf{2 0}}$ and Richardson ${ }^{21}$. Although majority of the studies have attested an elevated incidence of non-right/ left handedness in schizophrenia $^{22,23}$. Few researchers have also reported elevated right handedness ${ }^{\mathbf{2 4 , 2 5}}$ in the schizophrenic patients. A couple of studies have reported no association ${ }^{26}$ between them. Studies examining left-handedness in schizophrenics have not yet yielded conclusive findings ${ }^{27}$.

(Corresponding Author: Dr. Braj Bhushan PhD, Department of Humanities \& Social Sciences, Indian Institute of Technology, Kanpur-208016, India, Email: brajbhushan1@yahoo.com) 
Similarly the observations pertaining to hand lateralization and depression also seem to be divided. Several researchers have confirmed the prevalence of left-handedness in those scoring high on measures of depression ${ }^{\mathbf{2 8 , 2 9 , 3 0}}$ whereas some have reported just the opposite ${ }^{3,}$ 31; however, few studies did not find any association between the two ${ }^{32}$.

Handedness, footedness, eyedness and eardness are the peripheral indicators of hemispheric lateralization. However, eyedness has been questioned as a direct indicator of cerebral dominance ${ }^{4,33}$ because of crisscrossing of optic fibers; footedness seems a better indicator ${ }^{34}$, though both are least susceptible to environmental influences ${ }^{\mathbf{1 3}}$.

Though much emphasis has been given to handedness, few studies have investigated footedness $^{34}$ and eyedness $s^{4,33,35,36}$ too. Schiffman et al. ${ }^{13}$ have reported left or mixed footedness in schizophrenia. Like handedness, studies investigating eyedness as one of the indicators of laterality in schizophrenia have reported contrasting results. Schiffman et al. ${ }^{13}$ found left or mixed eye dominance in schizophrenics whereas pure left eye dominance has been reported by others ${ }^{36}$. A few have even reported mixed eye dominance $e^{\mathbf{4 , 3 3}}$ as well as null association $^{35}$.

In the case of depression, compared to the other indices of laterality, eardness seems to have consensus. Most of the studies have used either dichotic listening or visual hemifield tests. Although few arguments have been raised questioning the inferences drawn from studies using dichotic listening tests and visual half-field techniques, researchers in the area of laterality agree to its usage because preference (for eye and ear) correlates quite well with hemispheric differences. Bruder and associates ${ }^{29}, 37$ have reported left ear (right hemisphere) advantage on non-verbal dichotic listening task. Few more studies $^{\mathbf{3 8}}$ have reported similar findings. However, depressed patients show a right ear (left hemisphere) advantage on dichotic fused word or syllable tests ${ }^{29}$. These findings lack universal acceptance ${ }^{37,39}$. Adults with nonanxious major depression exhibited right ear (left hemisphere) preference for dichotic fused words whereas those with comorbid anxiety exhibited left ear (right hemisphere) advantage on dichotic complex tones. To the best of our knowledge studies describing footedness and eyedness in depression and eardness in schizophrenia are very few ${ }^{40}$.
Cultural evolution across the world has favoured right-handedness ${ }^{41}$. However, while complying with social sanctions forcing or anticipating right preference in Oriental societies (such as India), the influence of left and mixed handedness might not replicate the observations made on Western samples. Either because of the social sanctions, genetic pool, or developmental vulnerabilities, the hand preference pattern, especially lefthandedness, in Indians is different as compared to the western population. However, very few studies have been conducted on the Indian sample $\mathrm{e}^{\mathbf{1 8 , 2 5 , 4 0}}$ to investigate the lateralization pattern of those suffering from certain types of psychopathology. In the absence of sufficient studies it becomes essential to verify the nature of this pattern and its correlates.

Studies carried out on otherwise normal Indian sample have attempted to explore lateral preferences $^{42,43}$, hand preference and approval among major religious groups and hand clasping among endogamous groups ${ }^{44}$. The prevalence of left-handedness has always been low in India. Singh et al. ${ }^{\mathbf{4 3}}$ have reported it as low as 3.2 percent. They observed a significant sex difference between handedness and relative hand skill with females exhibiting higher right hand preferences. This has been corroborated by other researchers $^{\mathbf{4 2 , 4 4}}$. These studies have reported greater likelihood of left-handedness in men than the women. The prevalence of left handedness in later studies shows a small increase in the percentage of left-handers. For example, Mandal et al. ${ }^{45}$ has reported $6.78 \%$ left-handers.

Accepting the relationship between schizophrenia, depression and anomalous dominance the present study attempted to reexamine the contradictory findings on all the peripheral indices of laterality. Our primary aim was to find out the incidence of peripheral laterality in patients with schizophrenia and depression and to validate laterality as a predictor of both disorders. It was hypothesized that schizophrenics and depressed would show higher incidence of non-right handedness as compared to the non-patient controls.

\section{METHODOLOGY}

Subjects: A total of 147 male subjects (29 schizophrenics, 38 depressed, 80 non-patient controls) participated in the study. The patients selected for this study were undergoing treatment at the Institute of Mental Health, Amritsar, India. None of them were hospitalized at the time of data collection. Proper consent of the patients/ attendants and the consulting psychiatrist were 
obtained before conducting the study. The patient's group did not manifest acute symptoms and were communicative. The patients were selected for the study on the basis of their medical records and further diagnoses were done by the consulting psychiatrists adhering to the DSM-IV-TR diagnostic criteria for Schizophrenia and depressive disorder. Only those patients were included in the study whose symptom severity was rated within mild to moderate range by the treating psychiatrist. The schizophrenic patients were chronic exhibiting first-rank symptoms (thought disorder, inappropriate affect, delusions). The non-patient controls were from the adjoining cities. Unlike the patient group subjects in the NC group were selected from a pool of 342 subjects, $6.23 \%$ of which were left handed. They were drawn from the students and staff of various hospitals and universities. Because of this it was possible to strike some balance in terms of the number of subjects in the three categories. The NC group (N 80) had $21.25 \%$ left-handers, $23.75 \%$ mixedhanders, and 55\% right-handers. They had disclosed the absence of any history of psychiatric treatment or hospitalization in their disclosure form. However, this group was not screened for DSM IV-TR criteria.

The mean age and education of NC group were 23.36 (SD 2.28) and 12.26 (SD 3.74), respectively. The mean age and education of schizophrenic $\left(\mathrm{M}_{\mathrm{age}}=23.14, \mathrm{SD} 2.12 ; \mathrm{M}_{\text {education }}=\right.$ 10.31, SD 4.23) and depressed $\left(\mathrm{M}_{\mathrm{age}}=23.52, \mathrm{SD}\right.$ $3.26 ; \mathrm{M}_{\text {education }}=11.42$, SD 1.26) groups were also akin. The groups did not differ in terms of age and education. All the subjects belonged to middle socioeconomic class and conversed in Punjabi. They were also proficient in Hindi. Both the languages are read from left to right.

Measures: The Sidedness Bias Schedule ${ }^{45}$ was administered and subjects were asked to indicate their preference for unimanual activities on a 5point scale $(1=$ never, $5=$ always $)$. The subjects had to indicate their preference for left as well as the right hand on the 37-item questionnaire (Hand: writing, eating, throwing a ball, lifting a bucket full of water, using a spoon to stir, keying the lock, winding the lock, using scissors, painting, threading the needles, combing, brooming, screwing a nut, hammering a nail, opening the tap, switching the light, lighting a matchstick, tooth brushing, sorting cards, using knife, using racket for games, unscrewing the jar; Foot: kicking a ball, foot extended to climb a bus, foot on which body weight rested in standing posture, foot extended to ride a bicycle/vehicle, foot extended in long jump; Eye: seeing through a telescope, snapping photograph by camera, gun shooting, seeing through a keyhole, preferred eye to wink; Ear: hearing telephone when both hands are free, hearing a pocket-radio, matching musical tune, sensing tick movement in wrist watch, hearing a low voice).

Several authors have developed questionnaires to measure hand preference ${ }^{46-49}$. Concurrent researchers use either of them. However, as hand preference and performance have often turned uncorrelated for a variety of perceptuo-motor tasks $^{50,51}$ and cultural constraints play key role in determining hand preference, we opted to use Sidedness Bias Schedule developed by Mandal et al. ${ }^{45}$. This schedule (test-retest reliability $\mathrm{r}=$ 0.88 ) has been widely used in India ${ }^{52,53,54}$. On the basis of laterality quotient $(\mathrm{LQ}=$ right- left/right + left) subjects were classified as right-handers (+. 50 to +1.00$)$ and left-handers $(-.50$ to -1.00$)$ considering it a continuous variable. Intermediate scorers were classified as mixedhanders. The schedule also indicates bias (LQ) for foot, ear and eye.

\section{RESULTS}

The mean of LQs for hand, foot, eye, and ear preferences of the schizophrenic, depressed, and $\mathrm{NC}$ groups are given in table 1.

An interesting observation emerged out when cross tabulation was performed to see foot, eye, and ear dominance with respect to handedness. All the left -handed schizophrenics and depressed subjects had left-preference for foot, eye, and ear as well. Similar trend was seen in the mixed- handed schizophrenics and depressed subjects. All of them demonstrated mixed-foot, eye, and ear preferences. Further, all the righthanded schizophrenics showed right-eye preference but the foot $(23.07 \%$ mixed, $76.98 \%$ right) and ear preferences $(46.15 \%$ mixed, $53.85 \%$ right) were always non-left in nature. The right-handed depressed had mixed (5.71\%) as well as right $(94.29 \%)$ footedness. However, their eye and ear preferences were skewed in distribution. $2.86 \%$ of them had left, $20 \%$ mixed, and $77.14 \%$ had right eyedness. Similarly, 5.71\% had left, $22.86 \%$ mixed, and $71.43 \%$ had right earedness. Unlike the patient groups, the foot, eye, and ear scores of the right-handed normal controls were distributed. The footedness scores of the mixed-handers were also spread across the three categories (left, mixed, and right). However, they exhibited mixed-eye and ear preferences only. All the left-hander had left- 
footedness and mixed-earedness. $94.12 \%$ of them had mixed and 5.88\% right-eyedness. This indicated a possible relationship between psychopathology and extreme left-mixed dominance. Figure 1 illustrates the spread of LQ scores of all the four indices and symptoms.

Table 1: The distribution of left, mixed and right preferences in the three groups of subjects

\begin{tabular}{|c|c|c|c|c|c|c|c|c|c|c|c|}
\hline \multirow{2}{*}{$\mathbf{L Q}$} & \multirow{2}{*}{ Groups } & \multirow{2}{*}{$\mathbf{N}$} & \multicolumn{3}{|c|}{$\begin{array}{c}\% \text { distribution of } \\
\text { subjects }\end{array}$} & \multirow{2}{*}{ Mean } & \multirow{2}{*}{ SD } & \multicolumn{4}{|c|}{ Correlation (LQ) } \\
\hline & & & Left & Mixed & Right & & & Hand & Foot & Eye & Ear \\
\hline \multirow[t]{3}{*}{ Hand } & Schizophrenic & 29 & 6.89 & 3.45 & 89.66 & .75 & .45 & - & $.92 * *$ & $.71 * *$ & $.72 * *$ \\
\hline & Depressed & 38 & 5.26 & 2.64 & 92.1 & .77 & .37 & - & $.83^{* *}$ & $.95 * *$ & $.80^{* *}$ \\
\hline & $\mathrm{NC}$ & 80 & 21.25 & 23.75 & 55 & .26 & .44 & - & $.69 * *$ & $.27 *$ & $.49 * *$ \\
\hline \multirow[t]{3}{*}{ Foot } & Schizophrenic & 29 & 6.89 & 24.14 & 68.97 & .42 & .36 & & - & $.70^{* *}$ & $.67^{* *}$ \\
\hline & Depressed & 38 & 5.26 & 7.89 & 86.85 & .53 & .28 & & - & $.81 * *$ & $.78^{* *}$ \\
\hline & $\mathrm{NC}$ & 80 & 28.75 & 32.5 & 38.75 & .06 & .47 & & - & .13 & $.36 * *$ \\
\hline \multirow[t]{3}{*}{ Eye } & Schizophrenic & 29 & 6.89 & 3.45 & 89.66 & .46 & .38 & & & - & $.38^{*}$ \\
\hline & Depressed & 38 & 10.53 & 18.42 & 71.05 & .42 & .47 & & & - & $.84 * *$ \\
\hline & $\mathrm{NC}$ & 80 & 2.5 & 87.5 & 10 & .12 & .27 & & & - & $.37 * *$ \\
\hline \multirow[t]{3}{*}{ Ear } & Schizophrenic & 29 & 6.89 & 44.83 & 48.28 & .37 & .33 & & & & - \\
\hline & Depressed & 38 & 10.53 & 23.68 & 65.79 & .44 & .42 & & & & - \\
\hline & $\mathrm{NC}$ & 80 & 0 & 93.75 & 6.25 & .03 & .25 & & & & - \\
\hline
\end{tabular}

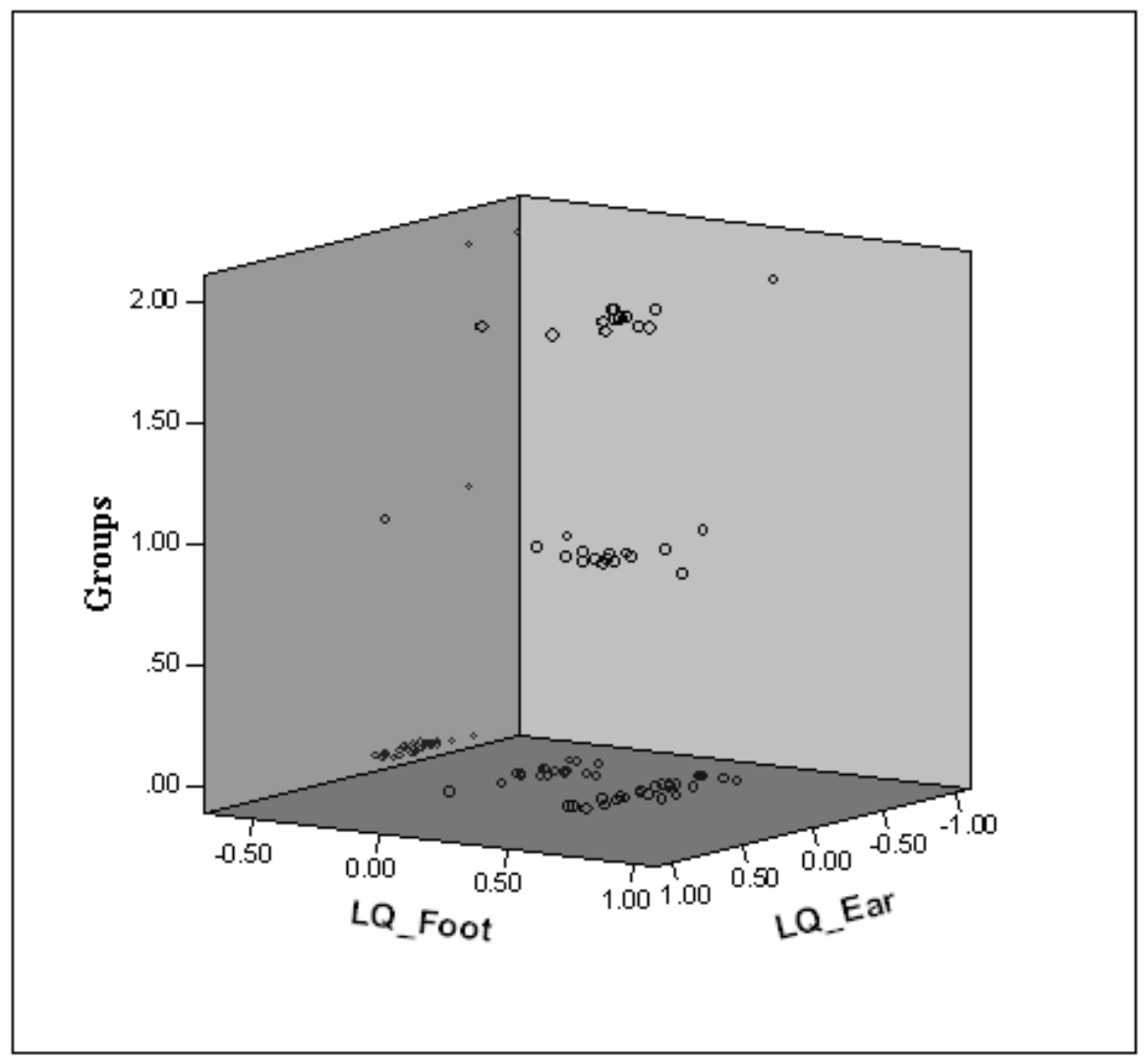

Groups: $0=$ Normal Controls, $1=$ Depressed, 2 = Schizophrenics

Figure 1: Scatterplot showing the relationship between footedness, earedness and symptoms 
Further, Pearson correlations were computed. The correlations between the LQs for hand, foot, ear, and eye are shown in Table 2 and 3. The correlations among all the variables were positive and highly significant when total LQ scores were taken into account. Similar observations were obtained when correlation was computed separately for the three groups except the foot-eye correlation $(\mathrm{r}=.13)$ in the NC group which did not turn significant.

Table 2: Intercorrelation matrix for LQs

\begin{tabular}{|l|l|l|l|l|}
\hline & LQ_hand & LQ_Foot & LQ_Eye & LQ_Ear \\
\hline LQ_hand & - & $.80^{* *}$ & $.63^{* *}$ & $.71^{* *}$ \\
\hline LQ_Foot & & - & $.49^{* *}$ & $.60^{* *}$ \\
\hline LQ_Eye & & & - & $.58^{* *}$ \\
\hline LQ_Ear & & & & - \\
\hline$*$ p $<.01$ & & - \\
\hline
\end{tabular}

Table 3: Regression analysis with LQ scores as predictors of symptoms

\begin{tabular}{|c|c|c|c|c|c|}
\hline Variables & B & Wald & df & $\operatorname{Exp}(B)$ & Significance \\
\hline \multicolumn{6}{|c|}{ Psychotic group - Normal Controls } \\
\hline LQ hand & -2.083 & 3.624 & 1 & .124 & .05 \\
\hline LQ foot & -.628 & .802 & 1 & .534 & NS \\
\hline LQ eye & -.607 & .749 & 1 & .545 & NS \\
\hline LQ ear & -1.695 & 4.964 & 1 & .184 & .05 \\
\hline \multicolumn{6}{|c|}{ Schizophrenic - Depressed groups } \\
\hline LQ hand & -2.749 & 1.798 & 1 & .064 & NS \\
\hline LQ foot & 6.918 & 4.910 & 1 & 1010.539 & .05 \\
\hline LQ eye & -2.189 & 1.799 & 1 & .112 & NS \\
\hline LQ ear & .034 & .001 & 1 & 1.035 & NS \\
\hline
\end{tabular}

As the outcomes were categorical logistic regression was carried out to assess the nature of relationship between LQ, schizophrenia, and depression. At the first step attempt was made to differentiate between normal controls and the patient groups $(0=$ patient groups, $1=\mathrm{NC})$. The obtained -2LL (143.228) and the goodness of fit (Hosmer \& Lemeshow $\chi^{2}=175.391$, df $=8, p$ $<.001$ ) were indicative of a better fit. The observed $\mathrm{R}$ square suggests that laterality quotient can predict schizophrenia and depression to certain extent (Cox and Snell R square $=.332$, Nagelkerke R square $=.444)$. The laterality quotient of hand and ear emerged as significant predictors of pathology (see table 3) with $B$ values indicating that schizophrenia and depressive disorder increases with decrease in LQ for handedness and eardness. It is imperative that decrease in LQ will result to increase in nonright hand and ear preferences. Therefore it can be interpreted that left and mixed hand and ear preferences are significant predictors of schizophrenia and depression, thus accepting the hypothesis.
Thereafter logistic regression was performed to see if LQ of the four indices can establish distinction between schizophrenics and depressed $(0=$ schizophrenics, $1=$ depressed $)$. There was a significant difference between foot preference of schizophrenics and depressed subjects (see table 3); -2LL value was 81.985 with smaller Cox and Snell $\mathrm{R}^{2}(.135)$ and Nagelkerke $\mathrm{R}^{2}(.181)$ values. Further, Hosmer and Lemeshow $\chi^{2}(11.567)$ did not turn significant

\section{DISCUSSION}

The present findings do not support high incidence of left handedness in schizophrenic and depressed subjects in comparison to the nonpatient controls. The higher incidence of right handedness in schizophrenics lends support to the findings of Taylor et al. ${ }^{\mathbf{2 4}}$ and Tiwari ${ }^{\mathbf{2 5}}$. The present findings of depressed subjects are in consonance with few earlier studies ${ }^{\mathbf{3}, 31}$. It merits mention here that the previous studies on Indian samples have come forward with contrasting findings. While Tiwari ${ }^{25}$ has reported right-hand dominance in schizophrenics, Upadhyay et al. ${ }^{\mathbf{1 8}}$ 
reports mixed-handedness in them. Present study supports the findings of Tiwari ${ }^{25}$.

The left and mixed-handed schizophrenics and depressed subjects exhibited extreme left and mixed preference for foot, eye, and ear, respectively. This finding is of substantive importance. According to Kang and Harris ${ }^{55}$ inconsistent left-handers show cross lateral preference for foot, whereas consistent lefthanders show uncrossed preference. These observations were made on normal subjects. The present findings show an extreme side-bias in left and mixed-handed schizophrenics and depressed subjects indicating a possible relationship between schizophrenia, depression, and cerebral lateralization.

Studies of western societies have yielded 9:1 (right:left) demographic ratio ${ }^{\mathbf{5 6}}$ with majority reporting a continuous $\mathrm{J}$-shaped distribution ${ }^{57}$. However, the handedness distribution in male right-handers reported by $\operatorname{Tan}^{58}$ was not Jshaped. Further, McManus ${ }^{56}$ has also advocated that the number of left-handers have increased from the last century. This distribution is visible in the schizophrenic and depressed groups reported in this study but the $\mathrm{NC}$ group seems to violate it. It merits mention that the $\mathrm{NC}$ group was selected from a pool of subjects where $6.23 \%$ were left-handers. Although the distribution of hand preference is not exactly $\mathrm{J}$ shaped in the Indian society the selection of mixed and right-handers for the present study has lead to the higher incidence rate of left and mixed peripheral lateralities in the $\mathrm{NC}$ group. It merits mention that social and parental pressure in the Indian society demands switching hand preference in those who are innately left-handed. However, we did not collect information about the history of hand change in the subjects.

The correlations between the LQs for hand, foot, ear, and eye are similar to those reported earlier $^{51,52}$. The nonsignificant correlation between hand and eye in the normal controls stands in isolation. Though Cannon et al. ${ }^{\mathbf{4}, 33}$ has questioned eyedness as a direct indicator of laterality several studies have reported modest correlation between hand and eye. It merits mention that Hebbal and Mysorekar ${ }^{59}$ failed to find any interrelationship between them.

It is also interesting to note that footedness, eyedness, and earedness are least susceptible to cultural influences. As crisscrossing of optic fibers blur the possibility of eyedness as an indicator of lateralization, the other two relatively influence-free measures (from cultural sanctions) have emerged as the predictors of schizophrenia and depression. Neurological investigations have endorsed certain abnormalities in the brains of persons with schizophrenia are restricted to or are worse usually in the left hemisphere. For example, schizophrenia subjects show thinning of the left parahippocampal gyrus and fusiform gyrus ${ }^{60}$, left temporal horn enlargement ${ }^{61}$, reduction in size of the left medial temporal $\operatorname{lobe}^{62}$, and loss of synaptic proteins from the left thalamus ${ }^{63}$. It merits mention that few investigators have come forth with neurobiological evidence signifying association between schizophrenia and reduced corticocortical $^{64} /$ fronto-temporal connectivity ${ }^{65}$. As the present study did not investigate the role of any such variable, it is not possible for us to lend support to the neurobiological observations simply on the basis of behavioural variables.

The present study has certain limitations also. It had only male sample. Hand preferences were not looked to separate out skilled and unskilled activities. Further studies on diverse and larger samples are needed beside the study of female population to avoid sample-specific characteristics obtained in the present study

\section{REFERENCES}

1. Flor-Henry P. Psychosis and temporal lobe epilepsy. A controlled investigation. Epilepsia 1969 Sep;10(3):363-95.

2. Hicks RE, Barton AK. Replication and refinements. Journal of Genetic Psychology 1975 Dec;127( $2^{\text {nd }}$ Half $): 323-24$.

3. Abrams R, Taylor MA. Cognitive dysfunction in melancholia. Psychol Med 1987 May; 17(2):359-62.

4. Cannon M, Jones P, Murray RM, et al. Childhood laterality and later risk of schizophrenia in the 1946 British birth cohort. Schizophr Res 1997 Aug;26(23):117-20.

5. Kohler C, Gur RC, Swanson CL, et al. Depression in Schizophrenia: I. Association with neuropsychological defecits. Biological Psychiatry 1998 Feb;43(3):165-72.

6. Kohler C, Swanson CL, Gur RC, et al. Depression in Schizophrenia: II. MRI and PET findings. Biological Psychiatry 1998 Feb;43(3):173-80.

7. Koreen AR, Siris SG, Chakos M, et al. Depression in first-episode schizophrenia. Am J Psychiatry 1993 Nov;150(11):1643-8.

8. Geschwind N, Behan P. Left handedness: Association with immune disease, migraine, and development learning disorder. 
Proceedings of the National Academy of Science 1982;79:5097-100.

9. Geschwind N, Galaburda AM. Cerebral lateralization: Biological mechanisms, associations, and pathology: I. A hypothesis and a program for research. Archives of Neurology 1985 May;42(5):428-59.

10. Geschwind N, Galaburda AM. Cerebral lateralization: Biological mechanisms, associations, and pathology: II. A hypothesis and a program for research. Archives of Neurology 1985 Jun;42(6):521-52.

11. Geschwind N, Galaburda AM. Cerebral lateralization: Biological mechanisms, associations, and pathology: III. A hypothesis and a program for research. Archives of Neurology 1985 Jul;42(7):63454.

12. Bryden MP, Steenhuis RE. Issues in the Assessment of Handedness. Cerebral Laterality: Theory and research. Erlbaum, Hillsdale, NJ; 1991.

13. Schiffman J, Pestle S, Mednick S, et al. Childhood laterality and adult schizophrenia spectrum disorders: a prospective investigation. Schizophr Res 2005 Jan;72(23):151-60.

14. Bruder GE. Dichotic listening in psychiatric patients. In Hugdahl, K. (Ed.) Handbook of Dichotic Listening: Theory, Methods, and Research. John Wiley \& Sons, New York 1988;527-563.

15. Miller EN, Fujioka TA, Chapman LJ, et al. Hemispheric asymmetries of function in patients with major affective disorders. $J$ Psychiatr Res. 1995 May-Jun;29(3):173-83.

16. Nasrallah HA, Keelor K, Van Schroeder C. Motoric lateralization in schizophrenic males. Am J Psychiatry 1981 Aug;138(8):1114-5.

17. Orr KGD, Cannon M, Gilvarry CM, et al. Schizophrenic patients and their first-degree relatives show an excess of mixedhandedness. Schizophr Res. 1999 Oct;39(3):167-76.

18. Upadhyay N, Mandal MK, Asthana AK, et al. Hand preference in patients with allergy, juvenile cancer, and schizophrenia. Laterality 2004 Jul;9(3):325-37.

19. Chapman JP, Chapman LJ. Handedness of hypothetically psychosis-prone subjects. $J$ Abnorm Psychol. 1987 May;96(2):89-93.

20. Kim D, Raine A, Triphon N, et al. Mixed handedness and features of schizotypal personality in a non-clinical sample. J Nerv Ment Dis. 1992 Feb;180(2):133-5.
21. Richardson AJ. Dyslexia, handedness and syndromes of psychosis-proneness. Int $J$ Psychophysiol.1994 Dec;18(3):251-63.

22. DeLisi LE, Svetina C, Razi K, et al. Hand preference and hand skill in families with schizophrenia. Laterality 2002 Oct;7(4):32132.

23. Taylor MA, Amir N. Sinister psychotics. Left-handedness in schizophrenia and affective disorder. J Nerv Ment Dis. 1995 Jan;183(1):3-9.

24. Taylor PJ, Dalton R, Fleminger JJ. Handedness in schizophrenia. $\mathrm{Br} J$ Psychiatry. 1980 Apr;136(4):375-83.

25. Tiwari G. Individual differences in sidedness bias. Unpublished doctoral dissertation, Banaras Hindu University, Varanasi, India, 1992.

26. Green MF, Satz P, Smith C, et al. Is there atypical handedness in schizophrenia? $J$ Abnorm Psychol. 1989 Feb;98(1):57-61.

27. Bryden MP, McManus IC, Bulman-Fleming MB. Evaluating the empirical support for the Geschwind-Behan-Galaburda model of cerebral lateralization. Brain Cogn. 1994 Nov;26(2):103-67.

28. Biederman J, Lapey KA, Milberger S, et al. Motor preference, major depression and psychosocial dysfunction among children with attention deficit hyperactivity disorder. J Psychiatr Res. 1994 Mar-Apr;28(2):17184.

29. Bruder GE, Quitkin FM, Stewart JW, et al. Cerebral laterality and depression: differences in perceptual asymmetry among diagnostic subtypes. $J$ Abnorm Psychol. 1989 May;98(2):177-86.

30. Overby LA. The relationship of handedness to depression in male and female college students. Personality and Individual Differences 1994 Apr;16(4):537-41.

31. Moscovitch M, Strauss E, Olds J. Handedness and dichotic listening performance in patients with unipolar endogenous depression who received ECT. Am J Psychiatry. 1981 Jul;138(7):988-90.

32. Yan SM, Flor-Henry P, Chen DY, et al. Imbalance of hemispheric functions in the major psychoses: A study of handedness in the People's Republic of China. Biol Psychiatry 1985 Aug;20(8):906-17.

33. Cannon M, Jones $\mathrm{P}$, Gilvarry $\mathrm{C}$, et al. Premorbid social functioning in schizophrenia and bipolar disorder: similarities and differences. Am J Psychiatry 1997 Nov;154(11):1544-50. 
34. Elias LJ, Bryden MP, Bulman-Fleming MB. Footedness is a better predictor than is handedness of emotional lateralization. Neuropsychologia. 1998 Jan;36(1):37-43.

35. Gur RE. Motoric laterality imbalance in schizophrenia. A possible concomitant of left hemisphere dysfunction. Arch Gen Psychiatry. 1977 Jan;34(1):33-7.

36. Giotakos O. Crossed hand-eye dominance in male psychiatric patients. Percept Mot Skills. 2002 Dec;95(3 Pt 1):728-32.

37. Bruder GE. Cerebral laterality and psychopathology: perceptual and eventrelated potential asymmetries in affective and schizophrenic disorders. In Davidson, $R$. J. \& Hugdahl, K. (Eds.), Brain Asymmetry. MIT Press, Cambridge 1995;661-692.

38. Johnson O, Crockett D. Changes in perceptual asymmetries with clinical improvement of depression and schizophrenia. J Abnorm Psychol. 1982 Feb;91(1):45-54.

39. Wale J, Carr V. Differences in dichotic listening asymmetries in depression according to symptomatology. $J$ Affect Disord. 1990 Jan;18(1):1-9.

40. Tiwari G, Mandal MK. Side bias in schizophrenia: hand, foot, eye, and ear. $J$ Gen Psychol 1998 Jan;125(1):39-46.

41. Leland KN, Kumm J, Van Horn JD, et al. A gene-culture model of human handedness. Behav Genet. 1995 Sep;25(5):433-45.

42. Singh M, Bryden MP. The factor structure of handedness in India. Int J Neurosci. 1994 Jan-Feb;74(1-4):33-43.

43. Singh M, Manjary M, Dellatolas G. Lateral preferences among Indian school children. Cortex. 2001 Apr;37(2):231-41.

44. Singh M, Kindu A. Hand preference and approval among Hindus and Muslims in India. Int J Neurosci. 1994 Mar;75(1-2):1929.

45. Mandal MK, Pandey G, Singh SK, et al. Hand preference in India. Int $J$ Psychol. 1992 Dec; 27(6): 433-442.

46. Annett M. A classification of hand preference by association analysis. $\mathrm{Br} J$ Psychol. 1970 Aug;61(3):303-21.

47. Chapman LJ, Chapman JP. The measurement of handedness. Brain Cogn. 1987 Apr;6(2):175-83.

48. Oldfield RC. The assessment and analysis of handedness: the Edinburgh inventory. Neuropsychologia. 1971 Mar;9(1):97-113.

49. Raczkowski D, Kalat JW, Nebes R. Reliability and validity of some handedness questionnaire items. Neuropsychologia. 1974 Jan;12(1):43-7.

50. Bryden MP, Singh M, Steenhuis RE, et al. A behavioral measure of hand preference as opposed to hand skill. Neuropsychologia. 1994 Aug;32(8):991-9.

51. Porac C, Coren S. Lateral Preferences and Human Behavior. Springer-Verlag, New York 1981.

52. Bhushan B, Khan SM. Laterality and accident proneness: a study of locomotive drivers. Laterality. 2006 Sep;11 (5):395404.

53. Bhushan B, Dwivedi CB, Mishra R, et al. Performance on a mirror-drawing task by non-right-handers. J Gen Psychol. 2000 Jul;127(3): 271-7.

54. Mandal MK, Bhushan B, Kumar A, et al. Side bias in alcohol and heroin addicts. Alcohol Alcohol. 2000 Jul-Aug;35(4):381-3.

55. Kang Y, Harris LJ. Handedness and footedness in Korean college students. Brain Cogn. 2000 Jun-Aug;43(1-3): 268-74.

56. McManus C. Right hand left hand: The origins of asymmetry in brains, bodies, atoms and cultures. Harvard University Press, Cambridge, MA 2002.

57. Borod JC, Caron HS, Koff E. Left-handers and right-handers compared on performance and preference measures of lateral dominance. Br J Psychol. 1984 May;75(Pt 2):177-86.

58. Tan U. The distribution of hand preference in normal men and women. Int $J$ Neurosci. 1988 Jul;41(1-2):35-55.

59. Hebbal GV, Mysorekar VR. Anatomical and behavioural asymmetries in right and left handers from India. Ann Anat. 2003 Jun;185(3):267-75.

60. McDonald B, Highley JR, Walker MA, et al. Anomalous asymmetry of fusiform and parahippocampal gyrus gray matter in schizophrenia: a postmortem study. $A m \mathrm{~J}$ Psychiatry 2000 Jan;157(1):40-7.

61. James ACD, Javaloyes A, James S, et al. Evidence for non-progressive changes in adolescent-onset schizophrenia. $\mathrm{Br} J$ Psychiatry. 2002 Apr;180(4):339-44.

62. DeLisi LE, Hoff AL, Schwartz JE, et al. Brain morphology in first-episode schizophrenic-like psychotic patients: a quantitative magnetic resonance imaging study. Biol Psychiatry 1991 Jan;29(2):15975.

63. Landén M, Davidsson P, Gottfries CG, et al. Reduction of the small synaptic vesicle

Copyrighted (C) by Dr. Arun Kumar Agnihotri. All right reserved 
protein synaptophysin but not the large dense core chromogranins in the left thalamus of subjects with schizophrenia. Biol Psychiatry. 1999 Dec;46(12):1698-702.

64. Hoffman RE, McGlashan TH. Neural network models of schizophrenia. Neuroscientist. 2001 Oct;7(5):441-54.
65. Ford JM, Mathalon DH, Whitfield S, et al. Reduced communication between frontal and temporal lobes during talking in schizophrenia. Biol Psychiatry. 2002 Mar;51(6):485-92. 